\title{
AHP STRATEGIC ANALYSIS FOR HEADQUARTERS
}

\author{
RE-LOCATION
}

\begin{abstract}
The purpose of this study is to demonstrate how AHP can be used in conjunction with an organizational change analysis framework (which is qualitative in nature), to address an important decision in a quantitative way. A brief explanation of the theoretical framework will be followed by a case study of an actual organization that used this approach to perform an organizational self-assessment and determine where to re-locate their headquarters.
\end{abstract}

Keywords: organizational change, corporate re-location.

\section{Introduction}

The target organization is a professional international association with more than 10,000 members worldwide. They have recently developed a new strategic plan for the organization and as a result they have engaged in a series of organizational changes. For this case study and as part of their initiatives, the authors were requested to evaluate, from a strategic point of view, where to re-locate their headquarters. Three cities had been proposed as result of the discussions: Pittsburgh (current location), Miami and Washington DC. This study shows how AHP can allow quantitative prioritization of alternatives using organizational analysis theoretical frameworks that are rather qualitative in principle. This study is important because the theoretical approach used here can be used by other organizations in different strategic choice settings.

\section{Literature Review}

Using AHP to provide strategic theoretical frameworks with quantitative results is not uncommon. The International Journal of the Analytic Hierarchy Process (IJAHP), probably the largest source of AHP applications, provides studies combining AHP with SWOT analysis (Yavuz and Baycan, 2014), with balanced scorecard frameworks (Marcarelli, 2017) and strategic analysis in general. Our study contributes and expands this body of knowledge by integrating, to our knowledge for the first time, a congruence evaluation model of organizational change (Tushman and O'Reilly, 2002) with an AHP BOCR analysis using Super Decisions software (Saaty, 2008; Mu and Pereyra-Rojas, 2017). More importantly, this integrated approach can be used by any organization facing strategic change decisions. 
ISAHP Article: A Style Guide for Paper Proposals To Be Submitted to the International Symposium on the Analytic Hierarchy Process 2018, Hong Kong, HK.

\section{Hypotheses/Objectives}

Our study intends to show an integrated approach using Tushman and O'Reilly (2002)'s model of organizational change with an AHP BOCR analysis (Saaty, 2008). This process will be illustrated via a case study involving a large professional organization facing the strategic choice of re-locating their headquarters.

\section{Research Design/Methodology}

This study is constituted of three parts: first, a strategic organization analysis using Tushman and O'Reilly (2002)'s change management model was performed. For this part, the results of an organization-wide survey and focus group interviews were used by the target organization strategic committee and related consultants to determine the new strategy of the organization.

Second, we mapped the strategic elements (i.e. mission, vision, critical tasks, culture, people and formal systems) in Tushman and O'Reilly (2002)'s change model. The identified critical tasks are very important for strategic success; therefore, any cityrelocation should foster (benefit) their successful execution. Next a congruence analysis of each critical task with respect to the other identified organizational critical success factors was performed. 


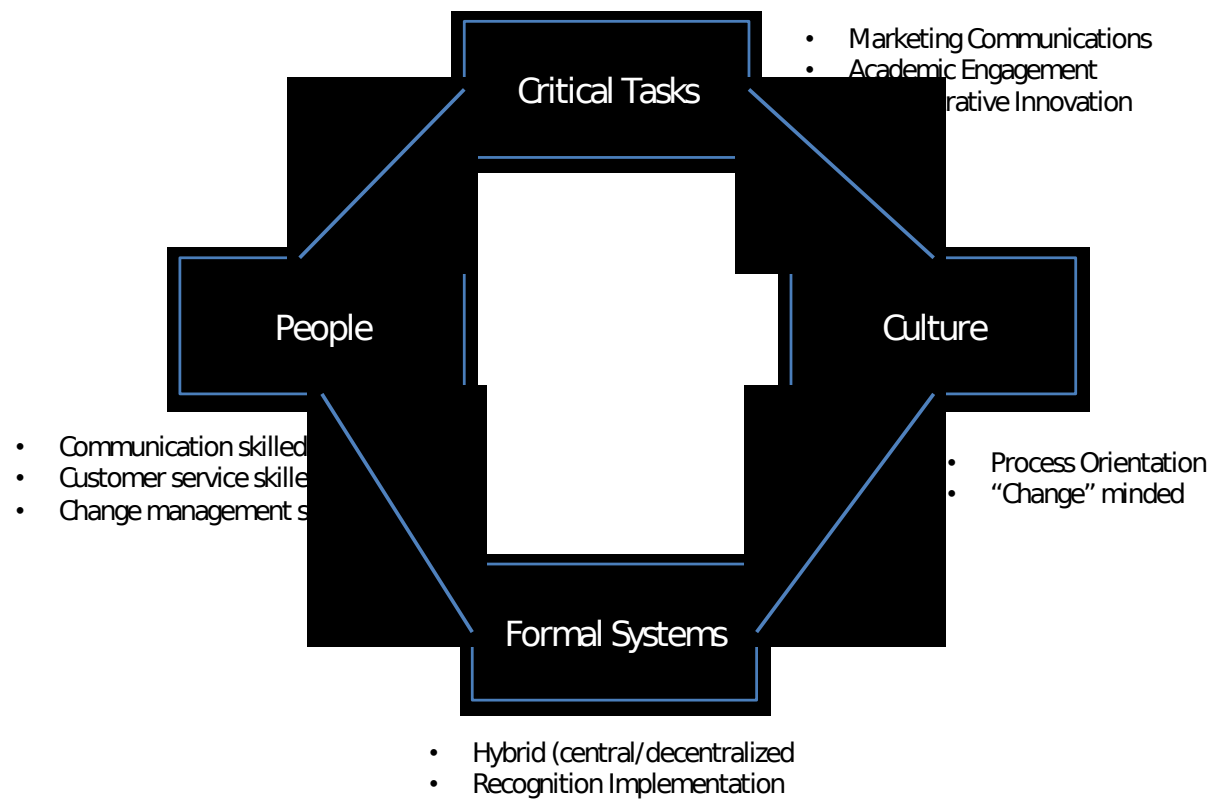

Figure 1 - Congruence (Partial View) Model for the new strategy>

Finally, the critical expected benefits (B), opportunities (O), costs $(\mathrm{C})$ and risks $(\mathrm{R})$ were identified based on the congruence analysis and this allowed performing an AHP BOCR analysis using the three potential re-location cities as alternatives. The comparison judgments were provided by the target organization's CEO based on the newly decided organizational strategy. The BOCR results provided the priorities, in terms of preferences, for the cities being evaluated. 


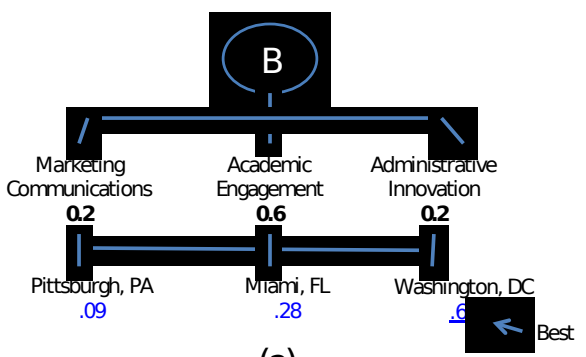

(a)

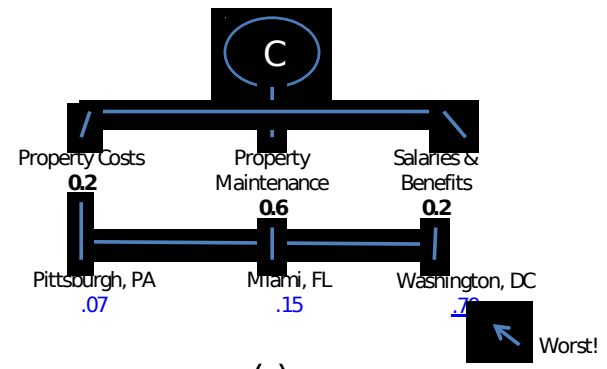

(c)

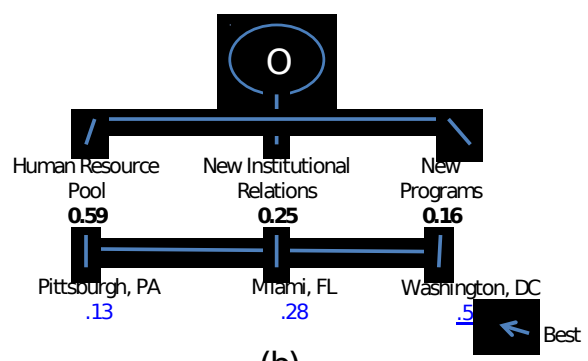

(b)

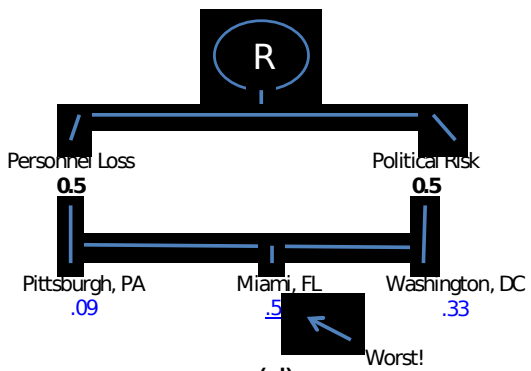

(d)

Figure 2 - BOCR Hierarchies: (a) Benefits, (b) Opportunities, (c) Costs and (d) Risks

\section{Data/Model Analysis}

The first and second parts of this study are qualitative in nature. For the third part, BOCR analysis, four hierarchies corresponding to Benefits, Opportunities, Costs and Risks were developed. The criteria were identified using the strategic congruence model as the starting point. The alternatives were constituted by the potential re-location cities in all the hierarchies. Finally, a multiplicative BOCR analysis was performed to prioritize the city re-location candidates: Pittsburgh, Miami and Washington DC.

Table 1 - BOCR Multiplicative Analysis

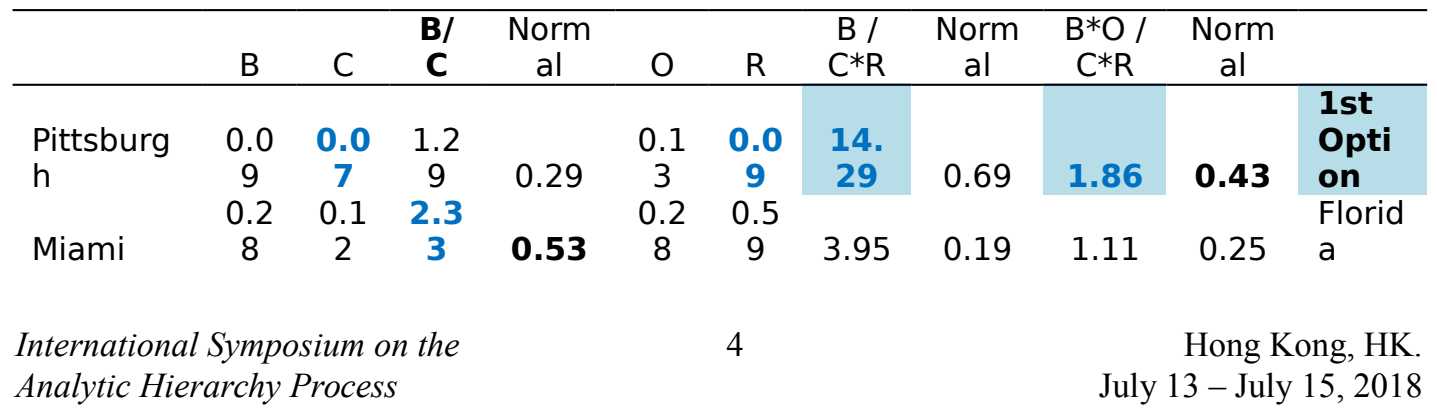




\begin{tabular}{lcccccccccccc}
\hline Washingt & $\mathbf{0 . 6}$ & & 0.7 & & $\mathbf{0 . 5}$ & 0.3 & & & & & $\begin{array}{l}\text { 2nd } \\
\text { Opti } \\
\text { on }\end{array}$ \\
\hline on & 3 & 0.8 & 9 & 0.18 & 8 & 3 & 2.39 & 0.12 & $\mathbf{1 . 3 8}$ & $\mathbf{0 . 3 2}$ & \\
\hline
\end{tabular}

\section{Limitations}

The re-location city prioritization has been done strictly in terms of strategic convenience and considerations such as financial ability to support the organization's operational expenses in each city were not considered.

\section{Conclusions}

This study has practical and theoretical value as follows: First, from a practical point of view, the organization under study has concluded that their best option for headquarters is to remain in the City of Pittsburgh, taking into account the alignment of the critical tasks according to their newly developed strategy. This result will be presented to the organization board of directors soon. Second, from a theoretical point of view, this study contributes to the stream of research integrating organizational analysis frameworks such as SWOT, Balanced scorecard and others with AHP. This paper specifically focuses on the integrated use, we understand for the first time, of AHP BOCR analysis with the Organizational Change Congruence Model (Tushman and O'Reilly, 2002) widely used in change management.

Finally, this paper - brief by necessity- only provides highlights and the backbone of the whole study that involved the development of the corporate strategy (surveying the members), the identification and prioritization of the critical tasks (done by a strategic committee), value chain analysis using AHP (to evaluate the impact of location on the primary activities) and finally the development of the congruence AHP model. The final goal of this study is to provide a complete AHP approach for the strategic decisionmaking process of an organization. Here we have presented only part of the study as related to the specific decision of headquarters location. The overall expectation is to develop an integrated strategic framework analysis with AHP that can be used as a template for strategic organizational analysis and decision-making.

\section{Key References}

Marcarelli, G. (2017). Evaluating healthcare organizations by a network model which integrates AHP with a revised-BSC. International Journal of the Analytic Hierarchy Process, 9(1). https://doi.org/10.13033/ijahp.v9i1.443.

Mu, E. and Pereyra-Rojas, M. (2017). Practical Decision Making: An Introduction to the Analytic Hierarchy Process (AHP) using Super Decisions v2. Springer International Publishing: Switzerland. 
ISAHP Article: A Style Guide for Paper Proposals To Be Submitted to the International Symposium on the Analytic Hierarchy Process 2018, Hong Kong, HK.

Saaty, T. L. (2008). Decision Making for Leaders. RWS Publications: Pittsburgh, PA.

Serra Costa, J., Borges, A., \& Machado, T. (2016). Analytic Hierarchy Process applied to industrial location: A Brazilian perspective on jeans manufacturing. International Journal of the Analytic Hierarchy Process, 8(1).

https://doi.org/https://doi.org/10.13033/ijahp.v8i1.210

Tushman, M. and O'Reilly, C. A. (2002). Winning through innovation: A practical guide to leading organizational change and renewal. Harvard Business School Publishing: Boston, MA.

Yavuz, F. and Baycan, T. (2014). Application of combined Analytic Hierarchy Process (AHP) and SWOT for integrated watershed management. International Journal of the Analytic Hierarchy Process, 6(1). https://doi.org/https://doi.org/10.13033/ijahp.v6i1.194

\section{Appendices}

$\mathrm{n} / \mathrm{a}$ 